\title{
Investigation of the effects of single-nucleotide polymorphisms in DNA repair genes on the risk of glioma
}

\author{
K. Gao, S.Q. Mu and Z.X. Wu \\ Tiantan Comprehensive Stroke Center, Beijing Tiantan Hospital, \\ Capital Medical University, Beijing, China \\ Corresponding author: Z.X. Wu \\ E-mail: swgaokun_tiantan@126.com
}

Genet. Mol. Res. 13 (1): 1203-1211 (2014)

Received December 19, 2012

Accepted July 23, 2013

Published February 27, 2014

DOI http://dx.doi.org/10.4238/2014.February.27.5

\begin{abstract}
Several single-nucleotide polymorphisms (SNPs) in DNA repair gene have been shown to affect DNA repair and to modify susceptibility to cancer. In this study, to investigate the role of these SNPs in glioma, we examined the potential association of 14 SNPs in DNA repair genes with the glioma risk in a Chinese population. We included 326 glioma cases and 376 cancer-free controls. Genotyping of the 14 SNPs was performed on 384-well plates on the Sequenom MassARRAY platform. Of the 14 SNPs, rs1799782 and rs1799793 did not display the Hardy-Weinberg equilibrium in the control group. Moreover, the genotype distribution differed significantly between the two groups for the SNPs rs25487, rs3218536, and rs1799793. The rs $25487 \mathrm{G} / \mathrm{G}$ genotype strongly and significantly increased the risk of glioma when compared with the rs25487 A/A genotype, indicated by an odds ratio $(\mathrm{OR})=2.23[95 \%$ confidence interval $(95 \% \mathrm{CI})=1.36$ 3.87]. The rs $25489 \mathrm{~A} / \mathrm{G}$ genotype was also significantly associated with increased risk of glioma when compared with the $\mathrm{A} / \mathrm{A}$ genotype $(\mathrm{OR}=$ $1.52 ; 95 \% \mathrm{CI}=1.03-2.35)$. In addition, rs 1799782 increased the risk of glioma $(\mathrm{OR}=1.89 ; 95 \% \mathrm{CI}=1.27-3.04)$, and a similar association was
\end{abstract}


found for $\mathrm{rs} 1800067(\mathrm{OR}=1.89 ; 95 \% \mathrm{CI}=1.21-3.07)$. In conclusion, the results of our study suggest that the rs25487, rs25489, rs1799793, and rs13181 SNPs are associated with an increased risk of glioma. These findings may be useful for identifying the genetic factors involved in the development of glioma to help devise more efficient strategies to prevent this disease.

Key words: DNA repair gene; Single-nucleotide polymorphisms; Glioma

\section{INTRODUCTION}

Glioma and meningioma are common tumors and account for almost $80 \%$ of all primary malignant brain tumors. Despite the advances in neurosurgery and adjuvant radiotherapy and chemotherapy, glioma and meningioma are generally associated with poor survival relative to other types of brain tumors (Bondy et al., 2008). To date, little is known about the etiology of glioma, which may involve interactions of multiple intrinsic and environmental factors (Connelly and Malkin, 2007; Bondy et al., 2008). Increasing evidence suggests that inheritance of risk factors plays some role in increased susceptibility of glioma, and most of this inherited risk is due to the coinheritance of multiple low-risk genetic variants. In normal cells, repair of damaged DNA is the main response to prevent the propagation of genetic errors and subsequent initiation and growth of tumors (Alberts et al., 2002; Vogelstein and Kinzler, 2004). Ionizing radiation is the only confirmed environmental risk factor for glioma because it produces several types of DNA damage, including oxidative damage to nucleotide bases, single- and double-strand breaks in DNA chains, and DNA-DNA or DNA-protein covalent cross links. The repair of these damage involves several molecular pathways for DNA repair such as base-excision repair, nucleotide excision repair, mismatch repair, double-strand break repair, and homologous recombination repair (Committee to Assess Health Risks from Exposure to Low Levels of Ionizing Radiation NR, 2006).

Previous studies have reported an association between glioma and several single-nucleotide polymorphisms (SNPs) in DNA repair genes (Wrensch et al., 2009; Shete et al., 2009; Liu et al., 2010). However, few studies have examined the association between DNA-repair genes and meningioma, and few reports have investigated the effects of gene-gene interactions on glioma risk. In this study, we performed a case-control study to assess the potential role of 14 SNPs in DNA repair genes in modifying the glioma risk in a Chinese population and investigated the role of gene-gene interactions in cancer risk.

\section{MATERIAL AND METHODS}

\section{Study population}

This case-control study included 326 subjects with glioma and 376 cancer-free subjects as a control group. Of the subjects with glioma, 358 were first diagnosed with intracranial glioma during 2008-2011 at the Beijing Tiantan Hospital, specialized in neurosurgery. Of these, $326(91.06 \%)$ of the eligible brain tumor patients agreed to participate; 222 patients 
were diagnosed with glioma and 104 with meningioma. The 376 control subjects had been admitted to our hospital for orthopedic injuries, digestive disorders, or musculoskeletal disorders. Of these, 341 (90.7\%) were enrolled in our study. Controls with known central nervous system-related diseases, a history of any types of cancer, and chemotherapy for unknown disease conditions were excluded. All the control subjects were frequency-matched to the glioma patients by age and gender. All subjects were questioned with a structured questionnaire in face-to-face interviews conducted by doctors or nurses.

Our study was approved by the Beijing Tiantan Hospital, and all subjects were asked to provide $5 \mathrm{~mL}$ venous blood.

\section{Genotyping}

DNA was extracted from the buffy-coat blood fractions with the TIANamp Blood DNA kit (Tiangen Biotech, Beijing, China). Genotyping of the 14 SNPs was performed on 384-well plates on the Sequenom MassARRAY platform (Sequenom, San Diego, CA, USA). Primers for polymerase chain reaction (PCR) amplification and single-base extension assays were designed by using the Sequenom Assay Design 3.1 software (Sequenom) according to manufacturer instructions (Table 1). PCR was carried out in a reaction volume of $20 \mu \mathrm{L}$, containing $50 \mathrm{ng}$ genomic DNA, $200 \mu \mathrm{M}$ dNTPs, $2.5 \mathrm{U}$ Taq DNA polymerase (Promega Corporation, Madison, WI, USA), and $200 \mu \mathrm{M}$ primers. The thermal cycling protocol used was as follows: $94^{\circ} \mathrm{C}$ for 2 min, followed by 35 cycles of $94^{\circ} \mathrm{C}$ for $30 \mathrm{~s}, 64^{\circ} \mathrm{C}$ for $30 \mathrm{~s}$, and $72^{\circ} \mathrm{C}$ for $1 \mathrm{~min}$. The PCR products were fractionated by electrophoresis on a $1.0 \%$ agarose gel to identify desired products. For quality control, genotyping was performed without knowledge of the case/control status of the subjects, and a random sample of $5 \%$ of cases and controls was genotyped again by different researchers. The reproducibility was $100 \%$.

\section{Statistical analyses}

Continuous variables are reported as means \pm standard deviation, whereas categorical variables are shown as frequencies and percentages. Demographic characteristics were compared between cases and controls by $\chi^{2}$ and Student $t$-tests. Hardy-Weinberg equilibrium (HWE) in the controls was assessed by using the $\chi^{2}$ test. Multiple models of inheritance (i.e., codominant, dominant, and recessive models) were chosen to evaluate associations between each SNP and glioma and meningioma risks. For each polymorphism, unconditional logistic regression analysis was used to calculate the odds ratios (ORs) and $95 \%$ confidence intervals (CIs) after adjusting for gender, age, ionizing radiation (IR), and family history of cancer. Statistical analyses were performed using the SPSS for Windows software (version 16.0 SPSS, Chicago, IL, USA). We analyzed the data using two-sided P values.

\section{RESULTS}

\section{Study subjects}

A total of 326 glioma and meningioma patients were included in our study, including 187 males and 139 females, with a mean age at diagnosis of $45.4 \pm 14.3$ years (Table 1). Of 
these, 222 patients were diagnosed with glioma and 104 patients with meningioma. The 376 control subjects had a mean age of $47.2 \pm 12.7$ years and included 203 males and 173 females. No significant difference was found between patient and control subjects in smoking and drinking status $(\mathrm{P}>0.05)$. It was noted that glioma and meningioma patients were more likely to have had a history of cancer and of higher IR exposure than the controls $(8.28 \mathrm{vs} 2.13 \%$, respectively, $\mathrm{P}<0.05$, for history of cancer; $6.75 v s 0.53 \%$, respectively, $\mathrm{P}<0.05$, for history of IR exposure).

\begin{tabular}{|c|c|c|c|c|c|c|}
\hline Characteristics & Case $(\mathrm{N}=326)$ & $\%$ & Control $(\mathrm{N}=376)$ & $\%$ & $\chi^{2}$ & $P$ value \\
\hline Age (mean $\pm \mathrm{SD}$; years) & $47.5 \pm 8.5$ & & $48.6 \pm 7.4$ & & & \\
\hline$<40$ & 57 & 17.48 & 70 & 18.62 & 0.27 & 0.88 \\
\hline $40-55$ & 126 & 38.65 & 139 & 36.97 & & \\
\hline$>55$ & 143 & 43.87 & 167 & 44.41 & & \\
\hline \multicolumn{7}{|l|}{ Gender } \\
\hline Male & 194 & 59.51 & 224 & 59.57 & 0.00 & 0.99 \\
\hline Female & 132 & 40.49 & 152 & 40.43 & & \\
\hline \multicolumn{7}{|l|}{ Smoking status } \\
\hline Never & 220 & 67.48 & 234 & 62.35 & 2.11 & 0.15 \\
\hline Ever & 106 & 32.52 & 142 & 37.65 & & \\
\hline \multicolumn{7}{|l|}{ Drinking status } \\
\hline Never & 191 & 58.59 & 201 & 53.57 & 1.86 & 0.17 \\
\hline Ever & 135 & 41.41 & 175 & 46.43 & & \\
\hline \multicolumn{7}{|l|}{ Ionizing radiation exposure } \\
\hline Never & 304 & 93.25 & 374 & 99.47 & 20.44 & $<0.05$ \\
\hline Ever & 22 & 6.75 & 2 & 0.53 & & \\
\hline \multicolumn{7}{|c|}{ History of cancer in the first relatives } \\
\hline No & 299 & 91.72 & 368 & 97.87 & 13.96 & $<0.05$ \\
\hline Yes & 27 & 8.28 & 8 & 2.13 & & \\
\hline \multicolumn{7}{|l|}{ Histological types } \\
\hline High-grade glioma & 148 & 45.31 & & & & \\
\hline Low-grade glioma & 178 & 54.69 & & & & \\
\hline
\end{tabular}

\section{Allele and genotype distributions of 14 SNPs and HWE}

Twelve of the 14 SNPs tested were confirmed to have distributions within the parameters of HWE for the control population, whereas rs1799782 and rs1799793 did not display HWE in the control group (Table 2). The minor allele frequencies among healthy controls were consistent with those in the Chinese population as recorded in the NCBI dbSNP database. In accordance with the allelic associations, the genotype distribution differed significantly between the two groups for SNPs rs25487, rs3218536, and rs 1799793. The minor allele frequencies of the SNPs rs25489, rs3734091, and rs1800067 were very low (i.e., frequencies of $<10 \%$ ).

\section{Polymorphisms of 14 SNPs and their association with glioma risk}

We further analyzed the effect of genotypes in different genetic models and on the different cancers (Table 3). The rs $25487 \mathrm{G} / \mathrm{G}$ genotype was found to significantly increase the risk of glioma when compared with the rs $25487 \mathrm{~A} / \mathrm{A}$ genotype in the codominant model, indicated by an $\mathrm{OR}=2.23(95 \% \mathrm{CI}=1.36-3.87)$. Moreover, significant associations between $\mathrm{rs} 25387$ and risk of glioma were detected in both dominant and recessive models $(\mathrm{OR}=1.50 ; 95 \% \mathrm{CI}=1.14$ 2.06 for the dominant model and $\mathrm{OR}=1.91 ; 95 \% \mathrm{CI}=1.14-3.28$ for the recessive model). Next, 
SNPs and glioma risk

1207

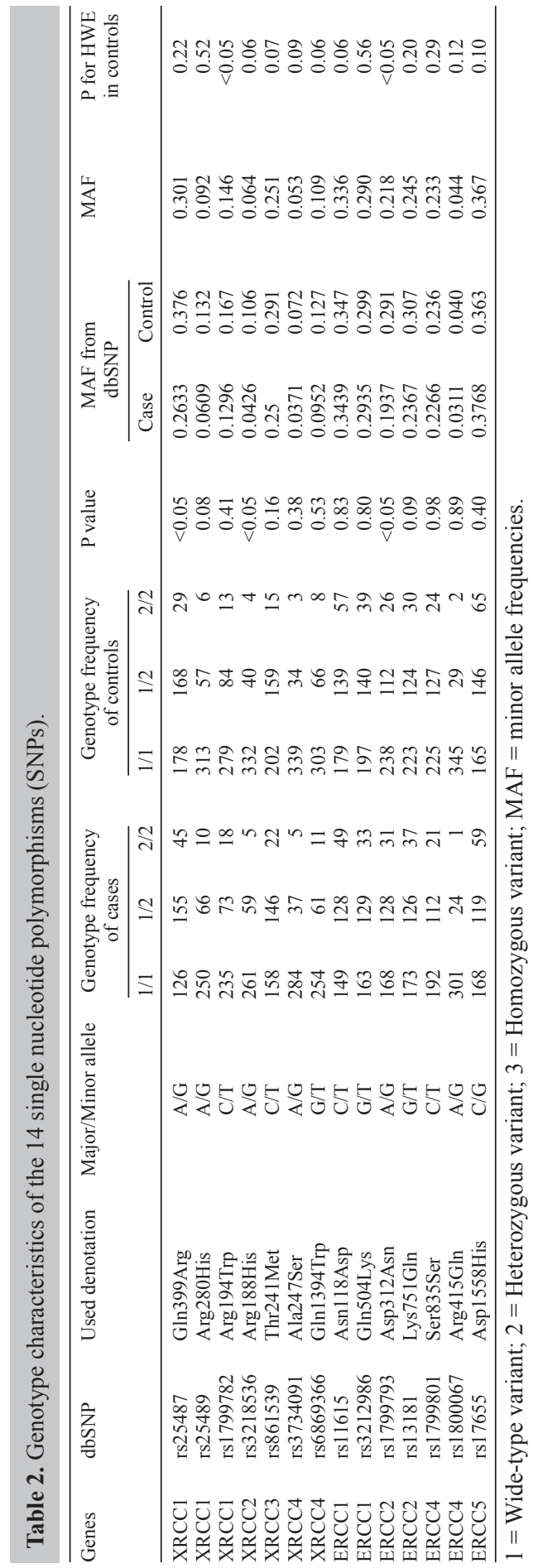


rs $25489 \mathrm{~A} / \mathrm{G}$ was identified as being significantly associated with an increased risk of glioma when compared with the rs $25489 \mathrm{~A} /$ A genotype $(\mathrm{OR}=1.52 ; 95 \% \mathrm{CI}=1.03-2.35)$ in the codominant model, and the dominant model analysis indicated that rs 25489 was associated with the risk of glioma $(\mathrm{OR}=1.56 ; 95 \% \mathrm{CI}=1.07-2.31)$. $\mathrm{rs} 1799782$ was significantly associated with a higher risk of glioma in both codominant and dominant models, indicated by $\mathrm{OR}=1.89(95 \% \mathrm{CI}$ $=1.27-3.04)$ and $\mathrm{OR}=1.86(95 \% \mathrm{CI}=1.21-2.94)$, respectively. A similar association was found for rs1800067, with $\mathrm{OR}=1.89(95 \% \mathrm{CI}=1.21-3.07)$ and $\mathrm{OR}=1.86(95 \% \mathrm{CI}=1.20-2.88)$ in codominant and dominant models, respectively.

\begin{tabular}{|c|c|c|c|c|c|c|}
\hline \multirow[t]{2}{*}{ Genes } & \multirow[t]{2}{*}{ Major/Minor allele } & \multirow[t]{2}{*}{ Case } & \multirow[t]{2}{*}{ Control } & \multicolumn{3}{|c|}{ Genotype frequency of cases [OR $(95 \% \mathrm{CI})]$} \\
\hline & & & & Codominant $^{1}$ & Dominant $^{1}$ & Recessive $^{1}$ \\
\hline XRCC1 Gln399Arg & $\mathrm{A} / \mathrm{A}$ & 126 & 178 & - & - & - \\
\hline \multirow[t]{2}{*}{ rs 25487} & $\mathrm{~A} / \mathrm{G}$ & 155 & 168 & $1.31(0.93-1.81)$ & $1.50(1.14-2.06)$ & $1.91(1.14-3.28)$ \\
\hline & $\mathrm{G} / \mathrm{G}$ & 45 & 29 & $2.23(1.36-3.87)$ & - & - \\
\hline $\mathrm{XRCC} 1 \mathrm{Arg} 280 \mathrm{His}$ & $\mathrm{A} / \mathrm{A}$ & 250 & 313 & - & - & - \\
\hline \multirow[t]{2}{*}{ rs 25489} & $\mathrm{~A} / \mathrm{G}$ & 66 & 57 & $1.52(1.03-2.35)$ & $1.56(1.07-2.31)$ & $1.95(0.63-6.60)$ \\
\hline & $\mathrm{G} / \mathrm{G}$ & 10 & 6 & $2.12(0.71-7.21)$ & - & - \\
\hline XRCC1 Arg194Trp & $\mathrm{C} / \mathrm{C}$ & 235 & 279 & - & - & - \\
\hline \multirow[t]{2}{*}{ rs1799782 } & $\mathrm{C} / \mathrm{T}$ & 73 & 84 & $1.03(0.72-1.56)$ & $1.15(0.81-1.76)$ & $1.63(0.75-3.71)$ \\
\hline & $\mathrm{T} / \mathrm{T}$ & 18 & 13 & $1.64(0.75-3.81)$ & - & - \\
\hline XRCC2 $\operatorname{Arg} 188$ His & $\mathrm{A} / \mathrm{A}$ & 261 & 332 & - & - & - \\
\hline \multirow[t]{2}{*}{ rs 3218536} & $\mathrm{~A} / \mathrm{G}$ & 59 & 40 & $1.89(1.27-3.04)$ & $1.86(1.21-2.94)$ & $1.45(0.31-7.39)$ \\
\hline & $\mathrm{G} / \mathrm{G}$ & 5 & 4 & $1.61(0.34-8.11)$ & - & - \\
\hline XRCC3 Thr241Met & $\mathrm{C} / \mathrm{C}$ & 158 & 202 & - & & - \\
\hline \multirow{2}{*}{ rs 861539} & $\mathrm{C} / \mathrm{T}$ & 146 & 159 & $1.19(0.88-1.61)$ & $1.26(0.92-1.71)$ & $1.75(0.85-3.68)$ \\
\hline & $\mathrm{T} / \mathrm{T}$ & 22 & 15 & $1.90(0.91-4.07)$ & - & - \\
\hline \multirow{3}{*}{$\begin{array}{l}\text { XRCC4 Ala247Ser } \\
\text { rs3734091 }\end{array}$} & $\mathrm{A} / \mathrm{A}$ & 284 & 339 & - & - & - \\
\hline & $\mathrm{A} / \mathrm{G}$ & 37 & 34 & $1.31(0.78-2.24)$ & $1.38(0.85-2.29)$ & $1.94(0.38-12.57)$ \\
\hline & $\mathrm{G} / \mathrm{G}$ & 5 & 3 & $2.03(0.40-13.2)$ & - & - \\
\hline XRCC4 Gln1394Trp & $\mathrm{G} / \mathrm{G}$ & 254 & 303 & - & & - \\
\hline \multirow{2}{*}{ rs6869366 } & $\mathrm{G} / \mathrm{T}$ & 61 & 66 & $1.12(0.76-1.69)$ & $1.20(0.81-1.71)$ & $1.65(0.61-4.73)$ \\
\hline & $\mathrm{T} / \mathrm{T}$ & 11 & 8 & $1.64(0.62-4.78)$ & - & - \\
\hline ERCC1 Asn118Asp & $\mathrm{C} / \mathrm{C}$ & 149 & 179 & - & - & - \\
\hline \multirow[t]{2}{*}{ rs11615 } & $\mathrm{C} / \mathrm{T}$ & 128 & 139 & $1.12(0.86-1.65)$ & $1.32(0.98-1.83)$ & $0.98(0.64-1.53)$ \\
\hline & $\mathrm{T} / \mathrm{T}$ & 49 & 57 & $1.06(0.67-1.73)$ & - & - \\
\hline ERCC1 Gln504Lys & $\mathrm{G} / \mathrm{G}$ & 163 & 197 & - & & - \\
\hline \multirow[t]{2}{*}{ rs 3212986} & $\mathrm{G} / \mathrm{T}$ & 129 & 140 & $1.12(0.82-1.55)$ & $1.12(0.84-1.55)$ & $0.98(0.58-1.65)$ \\
\hline & $\mathrm{T} / \mathrm{T}$ & 33 & 39 & $1.06(0.63-1.75)$ & - & - \\
\hline \multirow{3}{*}{$\begin{array}{l}\text { ERCC2 Asp312Asn } \\
\text { rs1799793 }\end{array}$} & $\mathrm{A} / \mathrm{A}$ & 126 & 178 & 168 & - & - \\
\hline & $\mathrm{A} / \mathrm{G}$ & 155 & 168 & $1.31(0.95-1.83)$ & $1.53(1.14-2.06)$ & $1.93(1.15-2.31)$ \\
\hline & $\mathrm{G} / \mathrm{G}$ & 45 & 29 & $2.22(1.29-3.96)$ & - & - \\
\hline ERCC2 Lys751Gln & $\mathrm{G} / \mathrm{G}$ & 250 & 313 & 173 & - & - \\
\hline \multirow[t]{2}{*}{ rs 13181} & $\mathrm{G} / \mathrm{T}$ & 66 & 57 & $1.45(0.96-2.19)$ & $1.54(1.07-2.31)$ & $1.95(0.64-6.61)$ \\
\hline & $\mathrm{T} / \mathrm{T}$ & 10 & 6 & $2.18(0.70-7.17)$ & - & - \\
\hline ERCC4 Ser835Ser & $\mathrm{C} / \mathrm{C}$ & 235 & 279 & 192 & - & - \\
\hline \multirow[t]{2}{*}{ rs 1799801} & $\mathrm{C} / \mathrm{T}$ & 73 & 84 & $1.05(0.73-1.52)$ & $1.13(0.78-1.57)$ & $1.64(0.75-2.71)$ \\
\hline & $\mathrm{T} / \mathrm{T}$ & 18 & 13 & $1.65(0.76-3.74)$ & - & - \\
\hline ERCC4 Arg415Gln & $\mathrm{A} / \mathrm{A}$ & 261 & 332 & 301 & - & - \\
\hline \multirow[t]{2}{*}{ rs 1800067} & $\mathrm{~A} / \mathrm{G}$ & 59 & 40 & $1.89(1.21-3.07)$ & $1.86(1.20-2.88)$ & $1.46(0.32-7.40)$ \\
\hline & $\mathrm{G} / \mathrm{G}$ & 5 & 4 & $1.61(0.34-8.13)$ & - & - \\
\hline \multirow{3}{*}{$\begin{array}{l}\text { ERCC5 Asp1558His } \\
\text { rs } 17655\end{array}$} & $\mathrm{C} / \mathrm{C}$ & 158 & 202 & 168 & - & - \\
\hline & $\mathrm{C} / \mathrm{G}$ & 146 & 159 & $1.27(0.89-1.71)$ & $1.24(0.91-1.71)$ & $1.75(0.86-3.73)$ \\
\hline & $\mathrm{G} / \mathrm{G}$ & 22 & 15 & $1.89(0.90-4.05)$ & - & - \\
\hline
\end{tabular}

${ }^{1}$ Adjusted for gender, age, ionizing radiation exposure history, and history of cancer in the first relatives.

\section{DISCUSSION}

To the best of our knowledge, our study is the first that has evaluated potential associa- 
tions between 14 SNPs in DNA repair genes and the risk of glioma and meningioma. We have shown that the rs25487, rs25489, rs1799793, and rs13181 SNPs are associated with increased risk of glioma. Although many studies have examined the association of DNA repair genes with the risk of glioma (Wang et al., 2012; Chen et al., 2012; Jacobs and Bracken, 2012), only 2 have comprehensively investigated the association of SNPs in DNA repair genes with glioma risk, and no study has shown such association in Chinese populations (Liu et al., 2009; Rajaraman et al., 2010). A study conducted on an American population with 373 Caucasian glioma cases and 365 cancer-free Caucasian controls assessed associations between glioma risk and 18 functional SNPs in DNA repair genes; $6 \mathrm{SNPs}$, including the $E R C C 1$ 3'-untranslated region (UTR), XRCC1 R399Q, APEX1 E148D, PARP1 A762V, MGMT F84L, and LIG1 5'-UTR, were identified as having a significant association with glioma risk (Liu et al., 2009). Another study also conducted in Americans included 565 cases and 495 controls and investigated 36 SNPs in 26 genes; its results indicated that the GLTSCR1 rs1035938, ERCC4 rs1800067, $E R C C 2$ rs 1799793, and PARP1 rs1136410 polymorphisms significantly increase the risk of glioma, whereas XRCC1 rs 1799782 decreases the glioma risk (Rajaraman et al., 2010).

A strong association observed in our study of 14 SNPs in the DNA repair pathway was the 2.23-fold increased risk of glioma in subjects with the rs $25487 \mathrm{G} / \mathrm{G}$ genotype. This association remained statistically significant even in dominant and recessive models after controlling for confounding factors. These results were consistent with several previous studies that have reported an association between polymorphisms in this SNP and glioma risk. In a recent study conducted in Americans, an association of the rs 25487 polymorphism with increased risk of glioma was detected in a survey including 373 glioma patients and 365 controls (Liu et al., 2009). Another study reported that the carriers of the rs $25487 \mathrm{G}$ allele have a 3.5 times greater risk for glioma (Yosunkaya et al., 2010). The rs25487 polymorphism has been a particular research focus because of its location within the region of the BRCT1-binding domain. Mutations in the BRCT1 domain of BRCA1 have been implicated in the altered function of this tumor suppressor gene (Sterpone and Cozzi, 2010). A previous study that measured the expression of the $X R C C 1$ gene reported that the 399 variant allele is associated with increased gene expression in breast cancer (Zipprich et al., 2010).

In addition, the results of our study have shown that rs 25489 was associated with glioma risk in codominant and dominant models. Although the previous 3 studies investigated the association between rs25487 and risk of glioma (Kiuru et al., 2008; Zhou et al., 2011; Wang et al., 2012), these studies did not find a significant association between rs25489 and the risk of glioma. Our study results also did not replicate previous reports of nonsignificant associations between rs25489 and glioma. These inconsistencies between our results and those of previous studies might be explained by differences in population background, source of control subjects, sample size, and also by chance. Confirmation of our observations is still needed and requires additional studies.

We have shown here that the rs3218536 SNP is significantly associated with glioma risk. The $\mathrm{G}$ allele of rs3218536, although not associated with glioma risk in previous studies, has been associated with a significant effect on risk of lung, colorectal, and breast cancer (Krupa et al., 2011; Romanowicz-Makowska et al., 2011, 2012), and it has been suggested that individuals carrying the G allele variant of this SNP are more susceptible to the effects of ionizing radiation. Further studies are strongly needed to validate the association between this SNP and glioma risk. 
No previous study has investigated the association between rs1800067 and glioma risk. However, several studies have investigated the association between rs1800067 and other cancers such as breast cancer, non-small cell lung cancer, bladder cancer, prostate cancer, and head and neck cancer (Chiu et al., 2008; Mandal et al., 2011; Zhou et al., 2012; Yin et al., 2012; Mittal et al., 2012). These studies suggested that individuals with the $T$ allele genotype are more susceptible to various cancers, and this genotype might decrease the effectiveness of anticancer treatments. It is hypothesized that the T allele of rs1800067 might lower the expression of XRCC4; thus, individuals with the $\mathrm{T}$ allele might be more impaired in double strand breakrepair pathways increasing the susceptibility to cancer when compared with $\mathrm{G} / \mathrm{G}$ genotypes.

Many approaches have aimed at identifying the genetic risk factors for glioma. In line with the rationale for this study, authors have suggested that some polymorphisms in genes of the DNA repair system are associated with various cancers (Kiuru et al., 2008; Chiu et al., 2008; Zhou et al., 2011; Mandal et al., 2011; Mittal et al., 2012). All of these findings strengthen the link between DNA repair systems and genome instability and carcinogenesis. Our study has comprehensively investigated the association of polymorphisms in genes of the DNA repair system and glioma. Its results suggested that rs25487, rs25489, rs1799793, and rs13181 are associated with an increased risk of glioma. Our findings may be useful for identifying the genetic conditions underlying glioma, to help devise more efficient strategies for preventing this disease.

\section{REFERENCES}

Alberts B, Johnson A, Lewis J, Raff M, et al (2002). The Cell Cycle and Programmed Cell Death. Molecular Biology of the Cell. Garland Science, New York.

Bondy ML, Scheurer ME, Malmer B, Barnholtz-Sloan JS, et al. (2008). Brain tumor epidemiology: consensus from the Brain Tumor Epidemiology Consortium. Cancer 113: 1953-1968.

Chen DQ, Yao DX, Zhao HY and Yang SJ (2012). DNA repair gene ERCC1 and XPD polymorphisms predict glioma susceptibility and prognosis. Asian Pac. J. Cancer Prev. 13: 2791-2794.

Chiu CF, Tsai MH, Tseng HC, Wang CL, et al. (2008). A novel single nucleotide polymorphism in XRCC4 gene is associated with oral cancer susceptibility in Taiwanese patients. Oral Oncol. 44: 898-902.

Committee to Assess Health Risks from Exposure to Low Levels of Ionizing Radiation NR (2006). Health Risks from Exposure to Low Levels of Ionizing Radiation: BEIR VII Phase 2. National Research Council, National Academies of Science, Washington.

Connelly JM and Malkin MG (2007). Environmental risk factors for brain tumors. Curr. Neurol. Neurosci. Rep. 7: 208-214.

Jacobs DI and Bracken MB (2012). Association between XRCC1 polymorphism $399 \mathrm{G} \rightarrow$ A and glioma among Caucasians: a systematic review and meta-analysis. BMC Med. Genet. 13: 97.

Kiuru A, Lindholm C, Heinavaara S, Ilus T, et al. (2008). XRCC1 and XRCC3 variants and risk of glioma and meningioma. J. Neurooncol. 88: 135-142.

Krupa R, Sliwinski T, Wisniewska-Jarosinska M, Chojnacki J, et al. (2011). Polymorphisms in RAD51, XRCC2 and XRCC3 genes of the homologous recombination repair in colorectal cancer - a case control study. Mol. Biol. Rep. 38: 2849-2854.

Liu Y, Scheurer ME, El-Zein R, Cao Y, et al. (2009). Association and interactions between DNA repair gene polymorphisms and adult glioma. Cancer Epidemiol. Biomarkers Prev. 18: 204-214.

Liu Y, Shete S, Hosking F, Robertson L, et al. (2010). Genetic advances in glioma: susceptibility genes and networks. Curr. Opin. Genet. Dev. 20: 239-244.

Mandal RK, Singh V, Kapoor R and Mittal RD (2011). Do polymorphisms in XRCC4 influence prostate cancer susceptibility in North Indian population? Biomarkers 16: 236-242.

Mittal RD, Gangwar R, Mandal RK, Srivastava P, et al. (2012). Gene variants of XRCC4 and XRCC3 and their association with risk for urothelial bladder cancer. Mol. Biol. Rep. 39: 1667-1675.

Rajaraman P, Hutchinson A, Wichner S, Black PM, et al. (2010). DNA repair gene polymorphisms and risk of adult meningioma, glioma, and acoustic neuroma. Neuro. Oncol. 12: 37-48. 
Romanowicz-Makowska H, Smolarz B, Zadrozny M, Westfal B, et al. (2011). Single nucleotide polymorphisms in the homologous recombination repair genes and breast cancer risk in Polish women. Tohoku J. Exp. Med. 224: 201-208.

Romanowicz-Makowska H, Smolarz B, Zadrozny M, Westfa B, et al. (2012). The association between polymorphisms of the RAD51-G135C, XRCC2-Arg188His and XRCC3-Thr241Met genes and clinico-pathologic features in breast cancer in Poland. Eur. J. Gynaecol. Oncol. 33: 145-150.

Shete S, Hosking FJ, Robertson LB, Dobbins SE, et al. (2009). Genome-wide association study identifies five susceptibility loci for glioma. Nat. Genet. 41: 899-904.

Sterpone S and Cozzi R (2010). Influence of XRCC1 Genetic Polymorphisms on Ionizing Radiation-Induced DNA Damage and Repair. J. Nucleic Acids pii: 780369. Doi: 10.4061/2010/780369.

Vogelstein B and Kinzler KW (2004). Cancer genes and the pathways they control. Nat. Med. 10: 789-799.

Wang D, Hu Y, Gong H, Li J, et al. (2012). Genetic polymorphisms in the DNA repair gene XRCC1 and susceptibility to glioma in a Han population in northeastern China: a case-control study. Gene 509: 223-227.

Wrensch M, Jenkins RB, Chang JS, Yeh RF, et al. (2009). Variants in the CDKN2B and RTEL1 regions are associated with high-grade glioma susceptibility. Nat. Genet. 41: 905-908.

Yin M, Liao Z, Liu Z, Wang LE, et al. (2012). Genetic variants of the nonhomologous end joining gene LIG4 and severe radiation pneumonitis in nonsmall cell lung cancer patients treated with definitive radiotherapy. Cancer 118: 528-535.

Yosunkaya E, Kucukyuruk B, Onaran I, Gurel CB, et al. (2010). Glioma risk associates with polymorphisms of DNA repair genes, XRCC1 and PARP1. Br. J. Neurosurg. 24: 561-565.

Zhou LP, Luan H, Dong XH, Jin GJ, et al. (2012). Association of functional polymorphisms of the XRCC4 gene with the risk of breast cancer: a meta-analysis. Asian Pac. J. Cancer Prev. 13: 3431-3436.

Zhou LQ, Ma Z, Shi XF, Yin XL, et al. (2011). Polymorphisms of DNA repair gene XRCC1 and risk of glioma: a casecontrol study in Southern China. Asian Pac. J. Cancer Prev. 12: 2547-2550.

Zipprich J, Terry MB, Brandt-Rauf P, Freyer GA, et al. (2010). XRCC1 polymorphisms and breast cancer risk from the New York Site of the Breast Cancer Family Registry: A family-based case-control study. J. Carcinog. 9: 4. 